\title{
A Potential Role of Vitamin D on Platelet Leukocyte Aggregation and Pathological Events in Sepsis: An Updated Review
}

\author{
Azzah Alharbi \\ Medical Microbiology and Parasitology \\ Department, King Abdulaziz University, \\ Jeddah, Saudi Arabia
}

\begin{abstract}
Vitamin D deficiency and sepsis are both significant global health problems. Insufficient vitamin $\mathrm{D}$ is considered to be a pathogenically relevant factor of sepsis-related deaths; however, a causal relationship has not yet been demonstrated. Recently, vitamin $\mathrm{D}$ has been an exciting field of research owing to the identification of vitamin D receptors on many extra skeletal tissues and cells, suggesting an unexpected role on body physiology, beyond its effects on bone homeostasis. However, while the role of vitamin D on bone health is widely understood and has been successfully translated into clinical applications and public health policies, recent evidence supporting its role in other physiological and pathological processes has not been fully established. In sepsis, there is an induction of local intracellular vitamin D activity by most immune cells, including lymphocytes, macrophages, neutrophils, and dendritic cells, as well as vascular endothelial cells, to ensure efficient clearance of infective microorganisms and mediate anti-inflammatory and tolerogenic effects. The literature suggests an association between low vitamin D levels and sepsis, but clinical trials have yielded contradictory results. A greater understanding of this role may improve disease management. This article reviews the available knowledge regarding vitamin $\mathrm{D}$ in immune function, emerging literature regarding the association between its deficiency and sepsis, as well as presenting its potential effect on platelet leukocyte aggregations (PLAs), a significant pathology in sepsis. It also summarizes clinical trials involving vitamin D supplementation during critical illness and sepsis and addresses the impact of relevant factors of sepsis pathogenesis on the efficacy of vitamin D supplementation, which could contribute to the reported inconsistencies. Looking ahead, further studies are required to uncover the possible modulatory relationship between vitamin D and sepsis to define better cut-offs for its levels, proper timing of its administration, and the optimum dosage for best management.
\end{abstract}

Keywords: infection, inflammation, cellular interaction, 25(OH)D3 deficiency

\section{Background}

Vitamin D (VD), is a steroid hormone and a crucial nutrient that is reported to control a wide range of physiological processes. ${ }^{1}$ Several sources of VD are available in the form of $\mathrm{D}_{2}$, known as ergocalciferol, and $\mathrm{D}_{3}$, known as cholecalciferol. $\mathrm{VD}_{2}$ is produced from ergosterol found mainly in fungi and also in some plants upon ultraviolet irradiation. Approximately $80 \%$ of $\mathrm{VD}_{3}$ is synthesized endogenously in the human skin as 7-dehydrocholesterol in response to ultraviolet
Correspondence: Azzah Alharbi Medical Microbiology and Parasitology Department, King Abdulaziz University, Jeddah, Saudi Arabia

Email Asalharbi3@kau.edu.sa 
ray exposure from sunlight, and about $20 \%$ is provided through diet. ${ }^{2-4}$ Inside the body, $\mathrm{VD}_{2}$ and $\mathrm{VD}_{3}$ undergo two consecutive steps of hydroxylation in the liver and then kidneys to be converted into their active compounds, 25(OH)D3 calcidiol (a clinical marker of plasmaV D level), and 1,25(OH)2D3 calcitriol, respectively. ${ }^{5}$

In addition to its well-known effects on calcium and phosphate metabolism to ensure bone health, VD has an emerging immune modulatory effect. VD is involved immune system regulation; it regulates the action of suppressor $\mathrm{T}$ lymphocytes, the synthesis of cytokines, and acts by modulating the processes of cellular apoptosis. ${ }^{6}$ In the 19th century, prior to the development of effective antibiotics, VD was serendipitously used to cure infections, such as tuberculosis, through sunlight exposure and administration of cod liver oil, which are the main sources of VD. ${ }^{7-11}$ The Nobel Prize for medicine or physiology in 1903 was awarded to Finsen for his contribution in treating lupus vulgaris, a skin disease caused by Mycobacterium tuberculosis with ultraviolet (UV) light. ${ }^{12-14}$ Since then, some cross-sectional studies have suggested an inverse correlation between lower levels of VD and increased infections, such as tuberculosis (TB) and upper respiratory tract infections. In 1977, it was reported that children with malnutritional rickets were more prone to lung infections associated with an apparent radiographic pulmonary abnormalities called "rachitic lung." 15 However, little attention has been paid to these studies owing to the subsequent discovery and application of antibiotic therapy for infections.

Over the past three decades, Finsen's work has received renewed attention as a consequence of multiple epidemiological studies showing a strong correlation between VD deficiency and the incidence of different infectious diseases, including pneumonia and sepsis. ${ }^{16-19}$ A significantly higher rate of such infections were reported during winter when exposure to sunlight, the major source of VD, is reduced. ${ }^{20,21}$ Since then, extensive studies of VD and incidence of infection have been published. Most of them focused on respiratory tract infections and consistently revealed the link between low VD plasma level (25 $(\mathrm{OH}) \mathrm{D} 3$ and the risk of acute respiratory infections. ${ }^{22,23}$ These findings were further confirmed by several randomized clinical trials (RCTs) that reported the protective effect of VD supplementation in reducing the risk of acute respiratory infections by $25 \%$ at doses of $400-1000$ IU per day for 12 months, particularly in those with a baseline of $<25 \mathrm{nmol} / \mathrm{l}^{24,25}$
During sepsis, there is growing evidence that VD deficiency is strongly associated with sepsis risk, pathogenesis, and outcomes as described later, ${ }^{26-29}$ but to date, these data could not be applied clinically. Several clinical trials aimed at analyzing the effects of supplementing VD on the outcomes of critical illness including sepsis have reported contradictory results as shown in Table 1 .

Given the fact that sepsis is the most common cause of critical illness, ${ }^{30}$ all RCTs investigating the effect of VD supplementation for critically ill and septic adult patients controlled with a placebo were retrieved. The databases of Pumped, Scopus, Medline, Embase, Web of Science, and Clinical Trials.gov were used to search for the following words: RCT, administration, supplementation, vitamin D, vitamin $D_{2}$, vitamin $D_{3}$, cholecalciferol, ergocalciferol, calcitriol, calcidiol, 25-hydroxyvitamin D3, 25(OH)D3, 1,25-dihydroxyvitamin $\mathrm{D} 3,1,25(\mathrm{OH}) 2 \mathrm{D} 3$, sepsis, critical ill, intensive care unit, septic shock. All critical and septic cases with low VD plasma levels $(25(\mathrm{OH}) \mathrm{D} 3 \leq 50 \mathrm{nmol} / \mathrm{l})$ at admission were eligible for inclusion.

In some studies, the administration of VD resulted in significant increases in leukocyte mRNA expression of cathelicidin (LL-37, antimicrobial peptide) ${ }^{31}$ and plasma cathelicidin, significant reductions in IL-1 $\beta$ and $1 \mathrm{~L}-6$ among septic patients, ${ }^{32}$ and showed a reduction in 30day ICU readmission in septic cases, a lower hospital death rate among critically ill patients with severe VD deficiency $(25(\mathrm{OH}) \mathrm{D} 3 \quad \leq 30 \mathrm{nmol} / \mathrm{l}),{ }^{33}$ a significant decrease in the duration of hospital stay, ${ }^{34}$ a reduction in the duration of respiratory support with mechanical ventilators and hospitalization, and a reduction in mortality rate in the ICU among the critically ill. ${ }^{35}$ However, other studies demonstrated the ineffectiveness of VD supplementation on the mortality rate and duration of hospital stay. $^{31,33,36,37}$

VD deficiency and sepsis are very common, ${ }^{20,26}$ and both conditions frequently coexist clinically. However, neither the effects of its deficiency on the pathogenesis of the disease and outcomes nor the effects of the disease itself on the correct assessment of VD status have yet been estimated. Such effects may contribute to the confusion about positivity and negativity of VD effects in the reported results so far. For the first time, this paper discusses the role of VD in the pathogenesis of sepsis with particular focus on platelet leukocyte aggregations (PLAs) and how it may reduce aggregate formation as well as their adherence to the endothelium to mitigate sepsis progression. It also addresses the impact of relevant factors of 







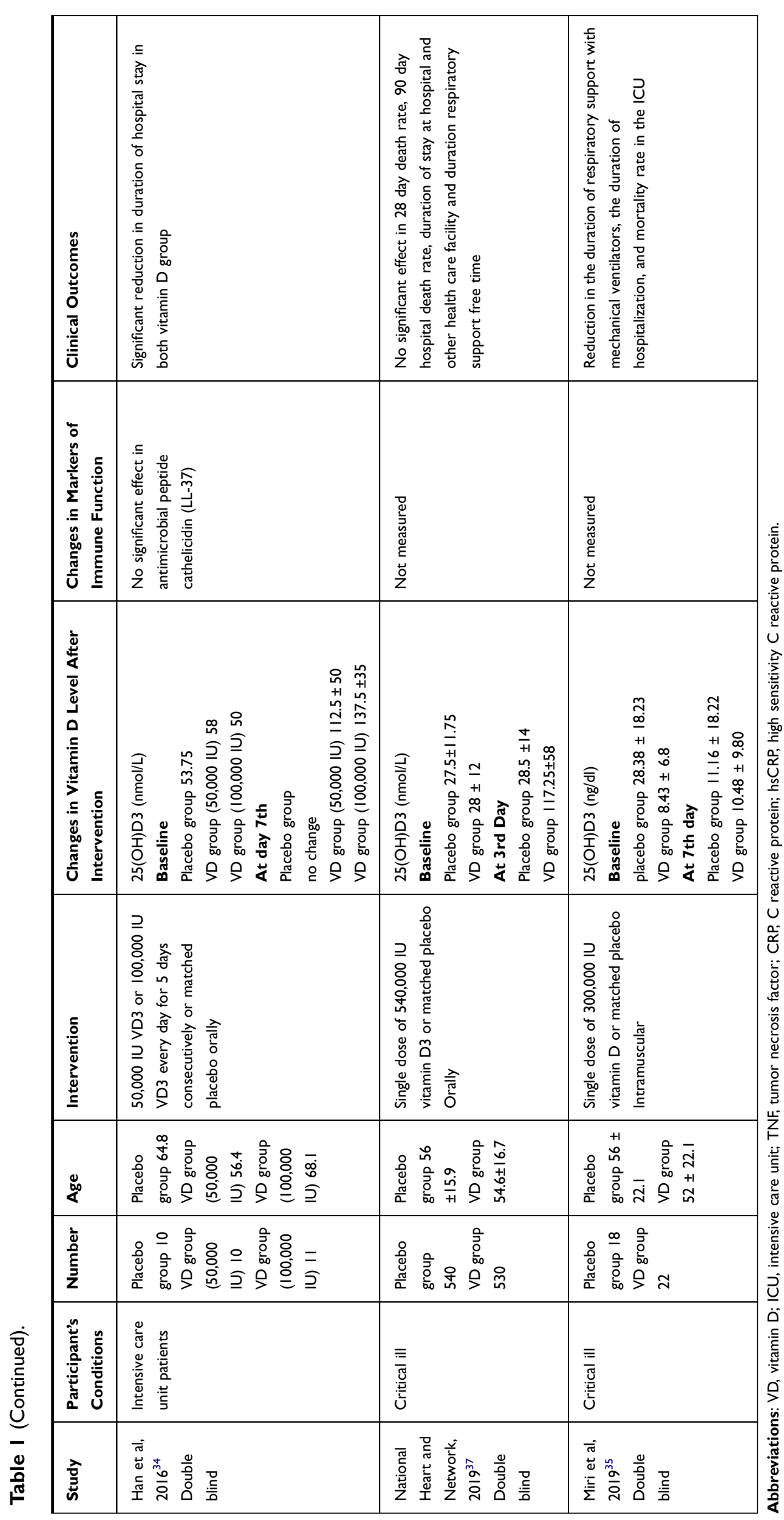


sepsis pathogenesis on the effectiveness of VD supplementation, which could contribute to clarification of the controversy in the reported results.

\section{Association Between Vitamin D Deficiency and Sepsis}

Sepsis is a life-threatening organ dysfunction caused by a dysregulated host response to an infection. ${ }^{38}$ It is a fastgrowing international health issue that imposes a substantial economic burden. Worldwide, it accounts for 48.9 million cases annually, resulting in more than 11 million deaths. ${ }^{39}$ In the UK, around 250,000 cases and 44,000 deaths of sepsis are reported every year. ${ }^{40,41}$ In the United States, 1.7 million cases are diagnosed and 270,000 of these cases die from sepsis. ${ }^{42}$ Very little is known about the estimates of the incidence and outcome of sepsis from developing countries, especially Saudi Arabia. However, all the available data confirm that sepsis is a serious cause of morbidity and mortality all over the world. Approximately two-thirds of septic patients are treated in intensive care units (ICU) with an annual estimated cost of $£ 15.6$ billion in the $\mathrm{UK}^{41}$ and $\$ 24$ billion in the United States. ${ }^{39}$ The current management guidelines applied for sepsis, including antibiotics and fluid replacement, are crucial and lead to significant improvement in clinical outcomes and reduction in mortality. ${ }^{43}$ However, some patients may still die and this maybe owing to the difficulty in assigning a patient's disease course to the relative over- or under inflammation that may occur, ${ }^{44}$ or microbial adaptation within the host in the form of acquiring resistance genes to the applied antibiotics (bacterial sepsis). ${ }^{45}$ Development of new adjunctive therapy to improve the disease might be helpful in those cases when standard care is not sufficient.

Although there is no consensus in the literature about 25(OH)D plasma concentrations used to define VD deficiency, it is a highly prevalent condition worldwide. ${ }^{46-48}$ The minimum agreement to date is that maintaining a plasma level of $25(\mathrm{OH}) \mathrm{D}$ above $30 \mathrm{nmol} / 1$ shields against VD deficiency-associated bone disorders; a lower 25(OH)D level could be used to define VD deficiency and should be prevented and treated. ${ }^{46}$ Based on the $25(\mathrm{OH}) \mathrm{D}$ cutoff of $<30 \mathrm{nmol} / \mathrm{l}$, VD deficiency is very common worldwide $^{49}$ with a reported prevalence of $13 \%$ in Europe, $5.9 \%$ in the United States, $7.4 \%$ in Canada, and more than $20 \%$ in many developing countries. ${ }^{50}$ The reported worldwide prevalence is much higher when VD deficiency is defined as $<50 \mathrm{nmol} / 1$. It is estimated as $40 \%$ in Europe, $24 \%$ in the United States, $37 \%$ in Canada, ${ }^{50}$ $34-22 \%$ in Africa, ${ }^{48}$ and $60 \%$ in Saudi Arabia. ${ }^{51}$

Low VD plasma levels have been observed in $79 \%$ to $98 \%$ of critical care unit patients, involving septic cases. ${ }^{52-}$ ${ }^{54}$ The risk of sepsis and its consequential outcomes such as death rate, length of hospital stay, and organ failure are positively correlated with VD deficiency. ${ }^{52,55}$ Trongtrakul and Feemuchang found that three-quarters of patients who are diagnosed with severe sepsis had a low plasma level of VD and a higher death rate, especially in cases where VD plasma levels were severely deficient $(25(\mathrm{OH}) \mathrm{D}<30 \mathrm{nmol} /$ 1). ${ }^{29}$ In the developed world, the number of new cases of sepsis as well as its related deaths are elevated during winter when low plasma levels of VD are detected, ${ }^{17}$ albeit that various seasonal factors are also implicated. ${ }^{56}$ Thus, restoring the VD to optimal plasma levels could have a valuable impact on sepsis development and outcomes. To date, the suggested recommended plasma concentrations of 25(OH)D that are considered sufficient or optimal vary in different settings. Concentrations of $>50$ $\mathrm{nmol} / 1$ are sufficient for bone health maintenance, although concentrations of $60-75 \mathrm{nmol} / \mathrm{l}$ are suggested for optimal beneficial effects on bone health. However, several studies note that higher levels of above $75 \mathrm{nmol} / 1$ are needed for optimal function of the immune system. ${ }^{57,58}$ Thus, it is very important to conduct further studies to determine optimal plasma levels for VD to exert its extra skeletal functions. In the developing world, data regarding the link between VD deficiency and sepsis is very limited. However, with the high reported prevalence of VD deficiency, increasing hospital admissions of septic patients with VD deficiency are to be expected. Future studies to estimate the VD levels among patients with sepsis and to correlate plasma level with various inflammatory mediators and disease outcomes are required.

\section{Vitamin D Mechanisms to Interfere with Sepsis Development}

In (bacterial) sepsis, damage and stress signals resulting from invading microorganisms and associated inflammatory responses stimulate intracellular VD activity locally to ensure efficient clearance of the microorganisms and mediate anti-inflammatory and tolerogenic effects. ${ }^{59}$ Stimulation of the TLR 2/1 pathway by binding to various pathogen-associated molecular patterns (PAMPs) results in induction of VDR and 1- $\alpha$-hydroxylase (CYP27B1) genes. 
Inflammatory mediators such as IFN $\gamma$, IL-15, and IL-17A contribute to 1- $\alpha$-hydroxylase (CYP27B1) gene activation. ${ }^{60,61}$ The majority of immune cells, such as lymphocytes, macrophages, neutrophils, and dendritic cells, as well as vascular endothelial cells have 25hydroxyvitamin D-1 $\alpha$-hydroxylase ( $1 \alpha$-OHase), which acts locally to convert 25-hydroxy-vitamin D (circulating form of VD), to its active compound $(1,25(\mathrm{OH}) 2 \mathrm{D}){ }^{62}$ Unlike the conventional renal activation of $\mathrm{VD}$, this conversion is regulated by 25 -hydroxy-vitamin D levels; thus, low concentration of 25-hydroxy-vitamin $\mathrm{D}$ interferes with its extra-skeletal actions. ${ }^{63,64}$ After activation, VD is translocated intracellularly, in association with a protein called VD binding protein and attach to its nuclear receptors (VDR) forming a complex. Subsequently, this complex attaches to the VD response element on DNA to regulate target gene transcription. ${ }^{60,65,66}$

VD receptor is expressed by most immune system cells. Thus, signaling through the VD receptor intensifies the local innate immune response by augmenting the release of antimicrobial peptides (AMPs) such as cathelicidin and LL-37, the active form of cathelicidin. ${ }^{67}$ Such AMPs induce a broad spectrum of antimicrobial activity mediated by cytokine release, including chemotaxis, phagocytosis, and programmed cell death. ${ }^{68} \mathrm{VD}$ reduces antigen presentation processes by decreasing the expression level of major histocompatibility complex (MHC) class II and co-stimulatory molecules, CD40, CD80, CD86, on antigen presenting cells (APCs) such as dendritic cells (DC), resulting in a more tolerogenic, immature state. ${ }^{69}$ It also has various effects on the activation status of cells mediating adaptive immunity. ${ }^{70-72}$ VD suppresses T lymphocytes (Th1) and their release of IL-2 and interferon gamma $(\operatorname{IFN} \gamma){ }^{73,74}$ Furthermore, the intracellular downstream signaling initiated by the VD-VDR complex in the vascular endothelium reduces cell activity and inflammatory response. ${ }^{75}$ Moreover, VD has an antiinflammatory effect. Four hours pre-incubation of immune cells extracted from blood of normal individuals with 100 $\mathrm{nM} 1,25(\mathrm{OH}) 2 \mathrm{D} 3$, reduced the production of several proinflammatory mediators (such as IL- $1 \beta$, TNF- $\alpha$, and IFN- $\gamma$ and IL-8), a 53-fold in response to their $24 \mathrm{~h}$-treatment with bacterial stimulus [heat-killed pneumococcal serotype 19F (HK19F)]. ${ }^{76}$ Another study found that activating blood immune cells isolated from VD deficient samples with TLR stimuli released a wide range of proinflammatory mediators, which were significantly decreased after VD treatment. ${ }^{77}$
VD exerts its anti-inflammatory actions by suppressing the gene expression of Toll-like receptor- 2 and Toll-like receptor- 4 , reducing $\mathrm{p} 38$ and $\mathrm{p} 42 / 42$ phosphorylation and its downstream signaling, as well as decreasing the release of reactive oxygen species. ${ }^{78}$ In addition, VD acts as a transcription factor to regulate the gene expression of several biological processes controlling immune response, such as cellular proliferation, differentiation, apoptosis, and angiogenesis. ${ }^{79}$ Furthermore, VD deficiency results in disturbance of the gut microbiome, ${ }^{80}$ which has an emerging role in sepsis pathogenesis as it increases the susceptibility to sepsis and enhances subsequent multiorgan failure. ${ }^{81,82}$ VD and VDR both play a significant role in maintaining the normal balance of gut microbiota, ${ }^{83}$ which in turn boosts immunity against enteric and systemic pathogens. ${ }^{84}$ Currently, multiple sepsis interventional approaches aimed at restoration of a balanced gut microbiota are under investigation. ${ }^{82}$ Thus, VD could be used as an adjuvant to enhance their therapeutic effects.

\section{Effect of Vitamin D on Platelet Leukocyte Aggregation}

Platelet leukocyte aggregates are liberally generated during sepsis and correlate significantly with diseases severity. ${ }^{85}$ The engagement of white blood cells (WBCs) with activated platelets producing cellular aggregates (moving freely in blood or attached to endothelial cells) contributed substantially to provoking and exacerbating organ dysfunction in septic cases. ${ }^{86}$ Thus, targeting this pathology at a specific time point in disease duration may limit the severity of sepsis outcomes such as vascular occlusion, decreased blood supply, and organ failure. PLA formation and their attachment to the endothelial lining of the vascular system may be triggered and propagated by a broad spectrum of activated mediators, such as adhesion molecules, proinflammatory cytokines, chemokines, complements, and procoagulant factors, as illustrated in Figure 1. This leads to sustained endothelial dysfunction, increased platelet and leukocyte reactivity, and activation of coagulation. ${ }^{87}$

As VDR is expressed genetically by most of the cells implicated in PLA formation, such as lymphocytes, neutrophils, macrophages, and vascular endothelial cells, ${ }^{88}$ VD may affect the formation of these aggregates. Recently, it was shown that healthy individuals with deficient VD have a high level of circulating PLAs and leukocyte endothelial adhesion. ${ }^{89}$ However, there is no 




Figure I Vitamin D effects on the cellular interaction of platelets, leukocytes and endothelium. Stimulation of platelets, leukocytes and endothelium by PAMPs, DAMPs and the released mediators in response to such stimulation results in the attachment of platelets to leukocytes and generating platelet leukocyte aggregates moving freely in the circulatory system or fixed to the stimulated endothelium. Several molecular interactions, which could be interfered by the action of VD, mediate this pathological phenomenon including P-Selectin with PSGL-I and $\alpha M \beta 2$ integrin with GPIb $\alpha$, (TREM-I) with its ligand on neutrophil, platelet JAM-3 with neutrophil $\alpha M \beta 2$ integrin, and LFA$I$ to its legend on platelet. These interactions induce further cell activation resulting in increased surface expression of adhesion receptors, degranulation, release of CD40L, Angiopoietin 2 (Ang2), inflammatory mediators, reactive oxygen species, tissue factor expression, microparticles release, thrombus and neutrophil extracellular trap formation (NET). Sites of Vitamin D (VD) effects are indicated in green. The figure was created using Biorender.com.

reported clinical data of the effect of VD administration on the extent of PLAs. It has also been found that VD reduces the expression of adhesion molecules required for platelet activation $^{90}$ and decreases homotypic platelet aggregation and platelet-platelet complexes. ${ }^{91}$ Therefore, it becomes crucial to consider the impact of VD and VDR in the formation of PLAs.

The first immune defense after infection is initiated by recognizing pathogen associated molecular patterns (PAMPs) and the released damage associated molecular pattern from tissue (DAMPs) by recognition receptors (RRs) such as toll-like receptors (TLRs). RRs are expressed by leukocytes and to a certain degree by endothelial cells and platelets, and result in the stimulation of intracellular signaling pathways and release of inflammatory cytokines such as IL-1, TNF $\alpha$, IL-6, IL-8, and IL12. ${ }^{92-94} \mathrm{VD}$ downregulates the gene expression of TLRs, thus reducing inflammatory responses. ${ }^{77,95}$ Moreover, VD decreases many proinflammatory mediators such as IL-6, IL-8, and $\mathrm{TNF} \alpha,{ }^{96}$ which themselves induce the stimulation of leukocytes, platelets, and endothelial cells and lead to the formation of PLAs.

The plasma level of VD is inversely correlated with mean platelet volume (MPV), a marker for platelet activity, noting that platelets with larger size are more active. $^{97,98}$ Activated platelets secrete CD40 ligand 
(CD40-L) into the blood, which interacts with CD40 receptors present on platelets to enhance its activation, ${ }^{99}$ and on leukocytes to augment its activation and generation of reactive oxygen species, ROS. ${ }^{100}$ Furthermore, it may bind to CD40 receptors expressed on vascular endothelial cells amplifying its activation and its expression of several adhesion molecules, such as ICAM and VCAM, on their surface and its production of the chemokine CCL2, thus mediating leukocyte recruitment.

Recently, it has been found that the administration of VD reduces gene expression of the CD40 ligand by blood cells, ${ }^{101}$ and serum levels of ICAM and VCAM that are secreted by stimulated endothelium. ${ }^{102}$ Angiopoietin 2 (Ang-2) is produced immediately from endothelial Weibel-Palade bodies upon their activation. Ang-2 interacts with Tie 2 receptors in a competitive manner to inhibit the protective effect of Ang- $1,{ }^{103,104}$ strengthen the activation of endothelium, and exaggerate the inflammation. ${ }^{105}$ Additionally, it interacts synergistically with other inflammatory cytokines to boost their actions; for example, sensitizing the vascular endothelium to stimulation with $\mathrm{TNF} \alpha .{ }^{106,107}$ It also induces the direct activation of polymorphonuclear cells towards the proinflammatory state. ${ }^{108}$ VD administration causes a considerable reduction in the serum level of angiopoietin-2. ${ }^{109}$ The interaction of triggering receptors expressed on myeloid cells (TREM-1) on platelets with their ligand on leukocytes is another mediator of PLAs. VD has been reported to inhibit the induced expression of TREM-1 in vitro. ${ }^{110}$

Tissue factor is expressed by activated endothelium, platelets, leukocytes, ${ }^{11-113}$ and their released microparticles, bearing procoagulant and proinflammatory properties, upon activation. ${ }^{14,115}$ It stimulates the extrinsic pathway of coagulation and generates thrombin and fibrinogen. These are important for the following reasons: Thrombin enhances adhesion molecule expression on the surface of the vascular endothelium such as $\mathrm{E}$ and $\mathrm{P}$ selection and production of von Willebrand factor (VWF) as well as several soluble secretory products, including platelet activating factor, Il-8, and angiopoietin 2. ${ }^{116-120}$ Fibrinogen stabilizes platelet leukocyte endothelial cell interaction by binding to Mac-1 on leukocytic cells and GPIIb/IIIa ( $\alpha \operatorname{IIb} \beta 3)$ on platelets and it also binds to CD11b/CD18 on leukocytic cells and intracellular adhesion molecule -1 (ICAM-1) on endothelial cells. ${ }^{121}$

VD downregulates the expression of tissue factor in vitro. Treatment of an activated (inflamed) endothelial cell line with VD suppresses gene expression for tissue factors and adhesion molecules. ${ }^{122}$ Furthermore, treatment with VD in patients with chronic kidney disease who have endothelial dysfunction with high serum levels of circulating microparticles leads to a significant reduction in the level of microparticles; ${ }^{123}$ it has also been found to inhibit microparticle release from a human endothelial cell line after their exposure to oxidative stress. ${ }^{124}$ Moreover, supplementing high doses of VD decreases thrombin production in severely VD deficient patients. ${ }^{125}$

\section{Potential Confounders of Vitamin D Supplementation in Sepsis}

The current in vitro and observational data, discussed in this review, argue for the usefulness of VD supplementation in sepsis. Several RCTs, as summarized in Table 1, have been conducted to evaluate the effect of VD supplementation on the clinical outcome of critical illnesses including sepsis, but their results are contradictory, and the correlation has not been confirmed in all studies.

The results obtained to date warrant further in-depth studies to determine the underlying mechanisms or factors that interfere with yielding the expected protective influences of VD on the progression and outcomes from sepsis. Herein, this part of the review addresses several factors which may confound the effectiveness of VD supplementation.

First, variability in the applied intervention methods regarding the dose, form, route, and duration of VD supplementation as well as heterogeneity of the population and sample size seen across the published RCTs could largely contribute to the reported mixed results. Second, there is a lack of clarity and consistency regarding definitions of VD deficiency and sufficiency in the literature, which produce a significant variation in the criteria of VD deficiency among RCTs. ${ }^{50,126,127}$ Thus, non-VD deficient cases could be involved in RCTs and have influenced the reported results.

Third, there is an inadequacy of prospective studies to determine the optimal VD dose for extra skeletal tissue functions. ${ }^{128}$ Moreover, the exact plasma concentration of VD to replace an insufficiency is controversial in patients with sepsis and its measurement must be interpreted cautiously. VD is physiologically distributed as free $(0.3 \%)$, or bound to either VD binding protein (DBP; 85\%) or albumin (15\%). Both DBP level and polymorphic variants affect the bioavailability of VD (free and bound to albumin) and this could affect the response to supplementation. 
In some patients, DBP is low due to protein catabolism ${ }^{129}$ or leakage to the extracellular matrix owing to increased vascular permeability. ${ }^{130}$ In the laboratory, VD sufficiency is commonly determined by measuring the plasma level of total vitamin $25(\mathrm{OH}) \mathrm{D} .{ }^{131}$ Thus, the bioavailability of free VD (active form) is increased and it can diffuse into most body cells. ${ }^{132,133}$ Additionally, the higher rate of polymorphism in the gene encoding VDBP (GC gene) results in DBP isoforms with different binding affinities to $\mathrm{VD},{ }^{134,135}$ which affect the bioavailability of VD. Additional VD supplementation therefore requires attention because it may lead to higher risk of hypercalcemia. ${ }^{63}$ Approximately $1 \%$ of mild hypercalcemia not requiring clinical intervention was reported among septic patients following VD administration. ${ }^{54}$ At the molecular level, any increase in extracellular (serum) calcium ions affects the inflammatory response. Extracellular $\mathrm{Ca}^{2+}$ act as a danger signal (DAMPs), and amplify inflammation. ${ }^{136}$ Moreover, septic patients may be classified as VD deficient based on their plasma level of total vitamin $25(\mathrm{OH})$ $\mathrm{D}$, even if the bioactive free form of VD is within normal values. ${ }^{130}$ Consequently, supplementation of VD may not produce the expected positive effects.

VD levels are important in the maintenance of circulating immunoglobulins and complement. A large study has documented, for low levels of VD, a positive association with $\operatorname{IgG} 2$ and $\mathrm{C} 4$ and a negative association for IgA (complement binding), IgG1, and C $3 .{ }^{137}$ These changes are of particular relevance in cases of systemic inflammatory reactions, which draw initially on intact mucosal barriers and a humoral component of the immune response. Depletion of complement components following overactivation and deposition in tissue (consumption in the blood phase) may be a determinant of overall outcome. ${ }^{138,139}$ Sepsis associated multiple-organ dysfunction, in which complement activation products and complement dysregulation have an undisputed pathogenic role, may well be influenced by specifically targeting pathways or components thereof. However, the timing of such an intervention for it to be effective and efficient may be difficult to judge. ${ }^{140}$ Septic patients suffer initially from an uncontrolled excessive inflammatory response followed by immune suppression. ${ }^{141}$ Therefore, proper timing of VD supplementation could significantly influence its supplementation outcomes. Modes of action may include pleiotropic effects on lipid metabolism, which are altered in the context of sepsis. ${ }^{142}$ VD deficiency is correlated with high levels of cholesterol, triglycerides, and low-density lipoproteins (LDL). ${ }^{143}$ VD supplementation leads to a reduction in lipid parameters, total cholesterol, very-low-density lipoproteins (VLDL), LDL, and triglycerides, ${ }^{144}$ which could be falsely interpreted as sepsis, because low lipid profiles are positively associated with poor sepsis outcome. ${ }^{145,146}$ Thus, it appears that timing and dose of VD supplementation in sepsis influence its effectiveness and this could be a contributing factor to the controversy in the reported results of interventional studies. Detailed understanding of the molecular basis of VD metabolism and the regulation of its bioavailability during the course of sepsis is required to determine its effectiveness.

\section{Conclusion}

VD deficiency is prevalent in cases with sepsis; ${ }^{26}$ thus, its deficiency may affect disease pathogenesis and aggravate the condition. VD has immunomodulatory effects. Restoration of VD plasma levels may limit disease progression through decreasing the abundance of DAMPs and PAMPs, inflammatory mediators, extent of PLAs formation and their adhesion to endothelia, and balancing the gut microbiota to fight systemic and enteric pathogens. However, data available from the literature regarding the influence of VD supplementation are conflicting in patients with sepsis and disagree with current evidence from in vitro and observational studies. Several factors may underestimate the expected positive effects. Further studies are warranted to elucidate the molecular interactions of VD with different players involved in the pathogenesis of sepsis (immune homeostasis). Thus, proper timing of VD supplementation, dose, form, and its sufficient plasma levels to be effective, as well as identifying patients who may benefit the most from supplementation with VD, need to be accurately determined in future clinical trials. Targeting the population with severe VD deficiency below $30 \mathrm{nmol} / \mathrm{l}$ is highly suggested for future trials.

\section{Acknowledgments}

The author would like to thank Prof. Suhad Bahijri, and Dr. Cordula Stover for her support in reviewing this manuscript.

\section{Disclosure}

The author declares no conflicts of interest. 


\section{References}

1. Tintut Y, Demer LL. Potential impact of the steroid hormone, vitamin $\mathrm{D}$, on the vasculature vitamin $\mathrm{D}$-hormones and cardiovascular disease. Am Heart J. 2021;239:147-153. doi:10.1016/j. ahj.2021.05.012

2. Christakos S, Dhawan P, Verstuyf A, Verlinden L, Carmeliet G. Vitamin D: metabolism, molecular mechanism of action, and pleiotropic effects. Physiol Rev. 2016;96:365-408. doi:10.1152/ physrev.00014.2015

3. Tripkovic L, Lambert H, Hart K, et al. Comparison of vitamin D2 and vitamin D3 supplementation in raising serum 25-hydroxyvitamin D status: a systematic review and meta-analysis. Am $J$ Clin Nutr. 2012;95:1357-1364. doi:10.3945/ajen.111.031070

4. Siddiqui M, Manansala JS, Abdulrahman HA, et al. Immune modulatory effects of vitamin D on viral infections. Nutrients. 2020;12:2879. doi:10.3390/nu12092879

5. Demer LL, Hsu JJ, Tintut Y. Steroid hormone vitamin D: implications for cardiovascular disease. Circ Res. 2018;122:1576-1585. doi:10.1161/CIRCRESAHA.118.311585

6. Dattola A, Silvestri M, Bennardo L, et al. Role of vitamins in skin health: a systematic review. Curr Nutr Rep. 2020;1-10.

7. Aranow C. Vitamin D and the immune system. $J$ Investig Med. 2011;59:881-886. doi:10.2310/JIM.0b013e31821b8755

8. Grant AH. The effect of Rachitic diets on experimental tuberculosis: III. resistance to tuberculosis decreased by adding codliver oil. Am Rev Tuberc. 1930;21:102-114.

9. Banyai AL. Topical application of codliver oil in tuberculosis: a preliminary report. Am Rev Tuberc. 1937;36:250-258.

10. Coulter JS, Carter HA. The treatment of pulmonary tuberculosis by ultraviolet radiation. $J$ Am Med Assoc. 1935;105:171-174. doi:10.1001/jama.1935.02760290005003

11. Gerstenberger HJ, Burhans CW. Treatment of extensive pulmonary tuberculosis with ultraviolet rays. Am $J$ Dis Child. 1927;33:54-73.

12. Finsen NR. Phototherapy: 1. The Chemical Rays of Light and Smallpox, 2. Light as a Stimulant, 3. The Treatment of Lupus Vulgarisby Concentrated Chemical Rays. Arnold; 1901.

13. Lang PO, Aspinall R. Vitamin D status and the host resistance to infections: what it is currently (not) understood. Clin Ther. 2017;39:930-945. doi:10.1016/j.clinthera.2017.04.004

14. Semon HC. The treatment of lupus erythematosus by krysolgan. Br Med J. 1927;2(3475):258. doi:10.1136/bmj.2.3475.258

15. Khajavi A, Amirhakimi G. The rachoitic lung: pulmonary findings in 30 infants and children with malnutritional rickets. Clin Pediatr (Phila). 1977;16:36-38. doi:10.1177/ 000992287701600106

16. Laaksi I, Ruohola J-P, Tuohimaa P, et al. An association of serum vitamin $\mathrm{D}$ concentrations $<40 \mathrm{nmol} / \mathrm{L}$ with acute respiratory tract infection in young Finnish men. Am $J$ Clin Nutr. 2007;86:714-717.

17. Upala S, Sanguankeo A, Permpalung N. Significant association between vitamin D deficiency and sepsis: a systematic review and meta-analysis. BMC Anesthesiol. 2015;15:1-11. doi:10.1186/ s12871-015-0063-3

18. Zhou W, Mao S, Wu L, Yu J. Association between vitamin D status and sepsis. Clin Lab. 2018;64:451-460. doi:10.7754/ Clin.Lab.2017.170919

19. McNally JD, Leis K, Matheson LA, Karuananyake C, Sankaran K, Rosenberg AM. Vitamin D deficiency in young children with severe acute lower respiratory infection. Pediatr Pulmonol. 2009;44:981-988. doi:10.1002/ppul.21089

20. Kempker JA, Han JE, Tangpricha V, Ziegler TR, Martin GS. Vitamin D and sepsis: an emerging relationship. DermatoEndocrinology. 2012;4:101-108. doi:10.4161/derm.19859
21. Yamshchikov A, Desai N, Blumberg H, Ziegler T, Tangpricha V. Vitamin D for treatment and prevention of infectious diseases: a systematic review of randomized controlled trials. Endocr Pract. 2009;15:438-449. doi:10.4158/EP09101.ORR

22. F Gunville C, M Mourani P, A Ginde A. The role of vitamin D in prevention and treatment of infection. Inflamm Allergy Drug Targets. 2013;12:239-245.

23. Ginde AA, Mansbach JM, Camargo CA. Association between serum 25-hydroxyvitamin D level and upper respiratory tract infection in the Third National Health and Nutrition Examination Survey. Arch Intern Med. 2009;169:384-390. doi:10.1001/archinternmed.2008.560

24. Martineau AR, Jolliffe DA, Hooper RL, et al. Vitamin D supplementation to prevent acute respiratory tract infections: systematic review and meta-analysis of individual participant data. $B M J$. $2017 ; 356$.

25. Jolliffe DA, Camargo CA Jr, Sluyter JD, et al. Vitamin D supplementation to prevent acute respiratory infections: a systematic review and meta-analysis of aggregate data from randomised controlled trials. Lancet Diabetes Endocrinol. 2021;9(5):276-292. doi:10.1016/S2213-8587(21)00051-6

26. Shojaei M, Sabzeghabaei A, Barhagh HV, Soltani S. The correlation between serum level of vitamin D and outcome of sepsis patients; a cross-sectional study. Arch Acad Emerg Med. 2019;7.

27. El-Gendy FM, Khattab AA, Naser RG, Abdel-Aziz AA. Association between vitamin D deficiency and sepsis in pediatric ICU. Menoufia Med J. 2021;34:210. doi:10.4103/mmj. mmj_210_19

28. Li Y, Ding S. Serum 25-Hydroxyvitamin D and the risk of mortality in adult patients with Sepsis: a meta-analysis. $B M C$ Infect Dis. 2020;20:1-10.

29. Trongtrakul K, Feemuchang C. Prevalence and association of vitamin $\mathrm{D}$ deficiency and mortality in patients with severe sepsis. Int J Gen Med. 2017;10:415. doi:10.2147/IJGM.S147561

30. Loftus TJ, Mira JC, Ozrazgat-Baslanti T, et al. Sepsis and critical illness research center investigators: protocols and standard operating procedures for a prospective cohort study of sepsis in critically ill surgical patients. BMJ Open. 2017;7:e15136. doi:10.1136/bmjopen-2016-015136

31. Leaf DE, Raed A, Donnino MW, Ginde AA, Waikar SS. Randomized controlled trial of calcitriol in severe sepsis. Am J Respir Crit Care Med. 2014;190:533-541. doi:10.1164/ rccm.201405-09880C

32. Quraishi SA, De Pascale G, Needleman JS, et al. Effect of cholecalciferol supplementation on vitamin D status and cathelicidin levels in sepsis: a randomized, placebo-controlled trial. Crit Care Med. 2015;43:1928. doi:10.1097/ CCM.0000000000001148

33. Amrein K, Schnedl C, Holl A, et al. Effect of high-dose vitamin D3 on hospital length of stay in critically ill patients with vitamin D deficiency: the VITdAL-ICU randomized clinical trial. JAMA. 2014;312:1520-1530. doi:10.1001/jama.2014.13204

34. Han JE, Jones JL, Tangpricha V, et al. High dose vitamin D administration in ventilated intensive care unit patients: a pilot double blind randomized controlled trial. J Clin Transl Endocrinol. 2016;4:59-65. doi:10.1016/j.jcte.2016.04.004

35. Miri M, Kouchek M, Dahmardeh AR, Sistanizad M. Effect of high-dose vitamin $\mathrm{D}$ on duration of mechanical ventilation in ICU patients. Iran J Pharm Res. 2019;18:1067.

36. Amrein K, Sourij H, Wagner G, et al. Short-term effects of high-dose oral vitamin D3 in critically ill vitamin D deficient patients: a randomized, double-blind, placebo-controlled pilot study. Crit Care. 2011;15:1-7. doi:10.1186/cc10120

37. National Heart, L.; Network, B.I.P.C.T. Early high-dose vitamin D3 for critically ill, vitamin D-deficient patients. $N$ Engl J Med. 2019;381:2529-2540. doi:10.1056/NEJMoa1911124 
38. Marik PE, Taeb AM. SIRS, qSOFA and new sepsis definition. J Thorac Dis. 2017;9:943. doi:10.21037/jtd.2017.03.125

39. Rudd KE, Johnson SC, Agesa KM, et al. Global, regional, and national sepsis incidence and mortality, 1990-2017: analysis for the Global Burden of Disease Study. Lancet. 2020;395:200-211. doi:10.1016/S0140-6736(19)32989-7

40. Dave M, Barry S, Coulthard P, et al. An evaluation of sepsis in dentistry. Br Dent J. 2021;230:351-357. doi:10.1038/s41415-0212724-6

41. Daniels R. Sepsis: the silent killer we should be stopping. Int J First Aid Educ. 2018;1:23. doi:10.21038/ijfa.2018.0005

42. Rhee C, Dantes R, Epstein L, et al. Incidence and trends of sepsis in US hospitals using clinical vs claims data, 2009-2014. JAMA. 2017;318:1241-1249. doi:10.1001/jama.2017.13836

43. Plevin R, Callcut R. Update in sepsis guidelines: what is really new? Trauma Surg Acute Care Open. 2017;2:e000088. doi:10.1136/tsaco-2017-000088

44. Hotchkiss RS, Monneret G, Payen D. Sepsis-induced immunosuppression: from cellular dysfunctions to immunotherapy. Nat Rev Immunol. 2013;13:862-874. doi:10.1038/nri3552

45. Khademi SH, Sazinas P, Jelsbak L. Within-host adaptation mediated by intergenic evolution in Pseudomonas aeruginosa. Genome Biol Evol. 2019;11:1385-1397. doi:10.1093/gbe/evz083

46. Roth DE, Abrams SA, Aloia J, et al. Global prevalence and disease burden of vitamin D deficiency: a roadmap for action in low-and middle-income countries. Ann $N$ Y Acad Sci. 2018;1430:44. doi:10.1111/nyas.13968

47. Giustina A, Adler R, Binkley N, et al. Consensus statement from 2 nd International Conference on Controversies in Vitamin D. Rev Endocr Metab Disord. 2020;21:89.

48. Mogire RM, Mutua A, Kimita W, et al. Prevalence of vitamin $\mathrm{D}$ deficiency in Africa: a systematic review and meta-analysis. Lancet Glob Health. 2020;8:e134-e142. doi:10.1016/S2214109X(19)30457-7

49. Pilz S, Zittermann A, Trummer C, et al. Vitamin D testing and treatment: a narrative review of current evidence. Endocr Connect. 2019;8:R27-R43.

50. Amrein K, Scherkl M, Hoffmann M, et al. Vitamin D deficiency 2.0: an update on the current status worldwide. Eur J Clin Nutr. 2020;74:1498-1513. doi:10.1038/s41430-020-0558-y

51. Al-Alyani H, Al-Turki HA, Al-Essa ON, Alani FM, Sadat-Ali M. Vitamin D deficiency in Saudi Arabians: a reality or simply hype: a meta-analysis (2008-2015). J Family Community Med. 2018;25:1.

52. Kempker JA, Tangpricha V, Ziegler TR, Martin GS. Vitamin D in sepsis: from basic science to clinical impact. Crit Care. 2012;16:316. doi:10.1186/cc11252

53. Azim A, Ahmed A, Yadav S, et al. Prevalence of vitamin D deficiency in critically ill patients and its influence on outcome: experience from a tertiary care centre in North India (an observational study). J Intensive Care. 2013;1:1-5. doi:10.1186/20520492-1-14

54. Amrein K, Papinutti A, Mathew E, Vila G, Parekh D. Vitamin $\mathrm{D}$ and critical illness: what endocrinology can learn from intensive care and vice versa. Endocr Connect. 2018;7:R304-R315. doi:10.1530/EC-18-0184

55. de Haan K, Groeneveld AJ, de Geus HR, Egal M, Struijs A. Vitamin D deficiency as a risk factor for infection, sepsis and mortality in the critically ill: systematic review and meta-analysis. Crit Care. 2014;18:660. doi:10.1186/s13054-014-0660-4

56. Fares A. Factors influencing the seasonal patterns of infectious diseases. Int J Prev Med. 2013;4:128.

57. Holick MF, Binkley NC, Bischoff-Ferrari HA, et al. Evaluation, treatment, and prevention of vitamin D deficiency: an Endocrine Society clinical practice guideline. J Clin Endocrinol Metab. 2011;96:1911-1930. doi:10.1210/jc.2011-0385
58. Helde Frankling M, Norlin A-C, Hansen S, Wahren Borgström E, Bergman P, Björkhem-Bergman L. Are vitamin D3 tablets and oil drops equally effective in raising S-25-hydroxyvitamin D concentrations? A post-hoc analysis of an observational study on immunodeficient patients. Nutrients. 2020;12:1230. doi:10.3390/ nu12051230

59. Chirumbolo S, Bjørklund G, Sboarina A, Vella A. The role of vitamin D in the immune system as a pro-survival molecule. Clin Ther. 2017;39:894-916. doi:10.1016/j.clinthera.2017.03.021

60. Medrano M, Carrillo-Cruz E, Montero I, Perez-Simon JA. Vitamin D: effect on haematopoiesis and immune system and clinical applications. Int J Mol Sci. 2018;19:2663. doi:10.3390/ijms19092663

61. Shin DM, Yuk JM, Lee HM, et al. Mycobacterial lipoprotein activates autophagy via TLR2/1/CD14 and a functional vitamin D receptor signalling. Cell Microbiol. 2010;12:1648-1665.

62. Lagishetty V, Liu NQ, Hewison M. Vitamin D metabolism and innate immunity. Mol Cell Endocrinol. 2011;347:97-105. doi:10.1016/j.mce.2011.04.015

63. Nair P, Venkatesh B, Center JR. Vitamin D deficiency and supplementation in critical illness - the known knowns and known unknowns. Crit Care. 2018;22:276. doi:10.1186/s13054-018-2185-8

64. Ahari MH, Pishbin E. Vitamin D and sepsis. Rev Clin Med. 2014;1:225-228.

65. Christakos S, Dhawan P, Benn B, et al. Vitamin D: molecular mechanism of action. Ann N Y Acad Sci. 2007;1116:340-348. doi:10.1196/annals. 1402.070

66. Jeon S-M, Shin E-A. Exploring vitamin D metabolism and function in cancer. Exp Mol Med. 2018;50:20. doi:10.1038/s12276018-0038-9

67. Chung C, Silwal P, Kim I, Modlin RL, Jo E-K. Vitamin D-cathelicidin axis: at the crossroads between protective immunity and pathological inflammation during infection. Immune Netw. 2020;20. doi:10.4110/in.2020.20.e12

68. Van Harten RM, Van Woudenbergh E, Van Dijk A, Haagsman HP. Cathelicidins: immunomodulatory antimicrobials. Vaccines. 2018;6:63. doi:10.3390/vaccines6030063

69. Prietl B, Treiber G, Pieber TR, Amrein K. Vitamin D and immune function. Nutrients. 2013;5:2502-2521. doi:10.3390/nu5072502

70. Hewison M. Antibacterial effects of vitamin D. Nat Rev Endocrinol. 2011;7:337. doi:10.1038/nrendo.2010.226

71. Gombart AF. The vitamin D-antimicrobial peptide pathway and its role in protection against infection. Future Microbiol. 2009;4:1151-1165. doi:10.2217/fmb.09.87

72. Youssef DA, Miller CW, El-Abbassi AM, et al. Antimicrobial implications of vitamin D. Dermato-Endocrinology. 2011;3:220-229. doi:10.4161/derm.3.4.15027

73. Wei R, Christakos S. Mechanisms underlying the regulation of innate and adaptive immunity by vitamin D. Nutrients. 2015;7:8251-8260. doi:10.3390/nu7105392

74. Sheikh V, Kasapoglu P, Zamani A, Basiri Z, Tahamoli-Roudsari A, Alahgholi-Hajibehzad M. Vitamin D3 inhibits the proliferation of T helper cells, downregulate CD4+ T cell cytokines and upregulate inhibitory markers. Hum Immunol. 2018;79:439-445. doi:10.1016/j.humimm.2018.03.001

75. Bozic M, Álvarez Á, de Pablo $\mathrm{C}$, et al. Impaired vitamin $\mathrm{D}$ signaling in endothelial cell leads to an enhanced leukocyte-endothelium interplay: implications for atherosclerosis development. PLoS One. 2015;10:e0136863. doi:10.1371/journal. pone. 0136863

76. Hoe E, Nathanielsz J, Toh ZQ, et al. Anti-inflammatory effects of vitamin D on human immune cells in the context of bacterial infection. Nutrients. 2016;8:806. doi:10.3390/nu8120806

77. Ojaimi S, Skinner NA, Strauss BJ, Sundararajan V, Woolley I, Visvanathan K. Vitamin D deficiency impacts on expression of toll-like receptor-2 and cytokine profile: a pilot study. $J$ Transl Med. 2013;11:1-7. doi:10.1186/1479-5876-11-176 
78. Calton EK, Keane KN, Newsholme P, Soares MJ. The impact of vitamin D levels on inflammatory status: a systematic review of immune cell studies. PLoS One. 2015;10:e141770. doi:10.1371/ journal.pone. 0141770

79. Umar M, Sastry KS, Chouchane AI. Role of vitamin D beyond the skeletal function: a review of the molecular and clinical studies. Int J Mol Sci. 2018;19:1618. doi:10.3390/ijms19061618

80. Haak BW, Wiersinga WJ. The role of the gut microbiota in sepsis. Lancet Gastroenterol Hepatol. 2017;2:135-143. doi:10.1016/ S2468-1253(16)30119-4

81. Haak BW, Prescott HC, Wiersinga WJ. Therapeutic potential of the gut microbiota in the prevention and treatment of sepsis. Front Immunol. 2018;9:2042. doi:10.3389/fimmu.2018.02042

82. Miller WD, Keskey R, Alverdy JC. Sepsis and the microbiome: a vicious cycle. J Infect Dis. 2021;223:S264-S269.

83. Akimbekov NS, Digel I, Sherelkhan DK, Lutfor AB, Razzaque MS. Vitamin D and the host-gut microbiome: a brief overview. Acta Histochem Cytochem. 2020;53:33-42. doi:10.1267/ahc.20011

84. Bassetti M, Bandera A, Gori A. Therapeutic potential of the gut microbiota in the management of sepsis. Crit Care. 2020;24:1-7. doi:10.1186/s13054-020-2780-3

85. Russwurm S, Vickers J, Meier-Hellmann A, et al. Platelet and leukocyte activation correlate with the severity of septic organ dysfunction. Shock. 2002;17:263-268. doi:10.1097/00024382200204000-00004

86. Wang X, Qin W, Sun B. New strategy for sepsis: targeting a key role of platelet-neutrophil interaction. Burns Trauma. 2014;2:23213868.135487

87. Alharbi A, Thomas R, Ali M, Thompson J, Stover C. Factors in homo and heterotypic aggregate formation in sepsis. Sepsis. 2016:1-11. https://leicester.figshare.com/articles/chapter/Factors_in_Homo_and_ Heterotypic_Aggregate_Formation_in_Sepsis/10235075.

88. Mohammad S, Mishra A, Ashraf MZ. Emerging role of vitamin D and its associated molecules in pathways related to pathogenesis of thrombosis. Biomolecules. 2019;9:649. doi:10.3390/biom9110649

89. Tay HM, Yeap WH, Dalan R, Wong SC, Hou HW. Increased monocyte-platelet aggregates and monocyte-endothelial adhesion in healthy individuals with vitamin D deficiency. FASEB $J$. 2020;34:11133-11142. doi:10.1096/fj.202000822R

90. Yildirim T, Solmaz D, Akgol G, Ersoy Y. Relationship between mean platelet volume and vitamin D deficiency in fibromyalgia. Biomed Res. 2016;27(4).

91. Sultan M, Twito O, Tohami T, Ramati E, Neumark E, Rashid G. Vitamin D diminishes the high platelet aggregation of type 2 diabetes mellitus patients. Platelets. 2019;30:120-125. doi:10.1080/09537104.2017.1386298

92. Sriskandan S, Altmann D. The immunology of sepsis. J Pathol. 2008;214:211-223. doi:10.1002/path.2274

93. Matsuda A, Jacob A, Wu R, et al. Novel therapeutic targets for sepsis: regulation of exaggerated inflammatory responses. J Nippon Med Sch. 2012;79:4-18. doi:10.1272/jnms.79.4

94. Cognasse F, Hamzeh H, Chavarin P, Acquart S, Genin C, Garraud O. Evidence of Toll-like receptor molecules on human platelets. Immunol Cell Biol. 2005;83:196-198. doi:10.1111/j.1440-1711.2005.01314.x

95. Sadeghi K, Wessner B, Laggner U, et al. Vitamin D3 downregulates monocyte TLR expression and triggers hyporesponsiveness to pathogen-associated molecular patterns. Eur J Immunol. 2006;36:361-370. doi:10.1002/eji.200425995

96. Adegoke SA, Smith OS, Adekile AD, Figueiredo MS. Relationship between serum 25-hydroxyvitamin D and inflammatory cytokines in paediatric sickle cell disease. Cytokine. 2017;96:87-93. doi:10.1016/j.cyto.2017.03.010

97. Korzonek-Szlacheta I, Hudzik B, Nowak J, et al. Mean platelet volume is associated with serum 25-hydroxyvitamin D concentrations in patients with stable coronary artery disease. Heart Vessels. 2018;33:1275-1281. doi:10.1007/s00380-018-1182-9
98. Park YC, Kim J, Seo MS, Hong SW, Cho ES, Kim J-K. Inverse relationship between vitamin $\mathrm{D}$ levels and platelet indices in Korean adults. Hematology. 2017;22:623-629. doi:10.1080/ 10245332.2017.1318334

99. Stokes KY, Granger DN. Platelets: a critical link between inflammation and microvascular dysfunction. $J$ Physiol. 2012;590:1023-1034. doi:10.1113/jphysiol.2011.225417

100. Rahman M, Roller J, Zhang S, et al. Metalloproteinases regulate CD40L shedding from platelets and pulmonary recruitment of neutrophils in abdominal sepsis. Inflamm Res. 2012;61:571-579. doi:10.1007/s00011-012-0446-6

101. Sharifi A, Vahedi H, Honarvar MR, et al. Vitamin D decreases CD40L gene expression in ulcerative colitis patients: a randomized, double-blinded, placebo-controlled trial. Turk J Gastroenterol. 2020;31:99. doi:10.5152/tjg.2020.181028

102. Naeini AE, Moeinzadeh F, Vahdat S, Ahmadi A, Hedayati ZP, Shahzeidi S. The effect of vitamin D administration on intracellular adhesion molecule-1 and vascular cell adhesion molecule-1 levels in hemodialysis patients: a placebo-controlled, double-blinded clinical trial. J Res Pharm Pract. 2017;6:16. doi:10.4103/2279-042X.200994

103. David S, Kümpers P, van Slyke P, Parikh SM. Mending leaky blood vessels: the angiopoietin-Tie2 pathway in sepsis. J Pharmacol Exp Ther. 2013;345:2-6. doi:10.1124/jpet.112.201061

104. Hegen A, Koidl S, Weindel K, Marmé D, Augustin HG, Fiedler U. Expression of angiopoietin-2 in endothelial cells is controlled by positive and negative regulatory promoter elements. Arterioscler Thromb Vasc Biol. 2004;24:1803-1809.

105. El-Banawy HS, Gaber EW, Maharem DA, Matrawy KA. Angiopoietin-2, endothelial dysfunction and renal involvement in patients with systemic lupus erythematosus. $J$ Nephrol. 2012;25:541-550. doi:10.5301/jn.5000030

106. Graham SM, Rajwans N, Tapia KA, et al. A prospective study of endothelial activation biomarkers, including plasma angiopoietin-1 and angiopoietin-2, in Kenyan women initiating antiretroviral therapy. BMC Infect Dis. 2013;13:1-11. doi:10.1186/1471-2334-13-263

107. Fiedler U, Reiss Y, Scharpfenecker M, et al. Angiopoietin-2 sensitizes endothelial cells to TNF- $\alpha$ and has a crucial role in the induction of inflammation. Nat Med. 2006;12:235-239. doi:10.1038/nm1351

108. Mussap M, Cibecchini F, Noto A, Fanos V. In search of biomarkers for diagnosing and managing neonatal sepsis: the role of angiopoietins. J Matern Fetal Neonatal Med. 2013;26:24-26. doi:10.3109/14767058.2013.830411

109. Johal P, Kamboj K, Kumar AY, Kumar V, Jha V. SUN-085 effect of cholecalciferol supplementation on serum angiopoietin-2 levels in CKD. Kidney Int Rep. 2020;5:S237. doi:10.1016/j.ekir.2020.02.611

110. Zhao Y, Guo Y, Jiang Y, Zhu X, Zhang X. Vitamin D suppresses macrophage infiltration by down-regulation of TREM-1 in diabetic nephropathy rats. Mol Cell Endocrinol. 2018;473:44-52. doi:10.1016/j.mce.2018.01.001

111. Ivanov II, Apta BH, Bonna AM, Harper MT. Platelet P-selectin triggers rapid surface exposure of tissue factor in monocytes. Sci Rep. 2019;9:1-10. doi:10.1038/s41598-019-49635-7

112. Zelaya H, Rothmeier A, Ruf W. Tissue factor at the crossroad of coagulation and cell signaling. $J$ Thromb Haemost. 2018;16:1941-1952.

113. Bouchard BA, Krudysz-Amblo J, Butenas S. Platelet tissue factor is not expressed transiently after platelet activation. Blood. 2012;119:4338-4339.

114. Takeshita J, Mohler ER III, Krishnamoorthy P, et al. Endothelial cell-, platelet-, and monocyte/macrophage-derived microparticles are elevated in psoriasis beyond cardiometabolic risk factors. $J$ Am Heart Assoc. 2014;3:e000507. doi:10.1161/ JAHA.113.000507 
115. Creager M, Loscalzo J, Beckman JA. Vascular Medicine E-Book: A Companion to Braunwald's Heart Disease. Elsevier Health Sciences; 2012.

116. Sugama Y, Tiruppathi C, Andersen T, Fenton J, Malik A. Thrombin-induced expression of endothelial P-selectin and intercellular adhesion molecule-1: a mechanism for stabilizing neutrophil adhesion. J Cell Biol. 1992;119:935-944. doi:10.1083/ jcb.119.4.935

117. Meiring M, Allers W, Le Roux E. Tissue factor: a potent stimulator of Von Willebrand factor synthesis by human umbilical vein endothelial cells. Int J Med Sci. 2016;13:759. doi:10.7150/ ijms. 15688

118. Ueno A, Murakami K, Yamanouchi K, Watanabe M, Kondo T. Thrombin stimulates production of interleukin-8 in human umbilical vein endothelial cells. Immunology. 1996;88:76-81. doi:10.1046/j.1365-2567.1996.d01-635.x

119. Heller R, Bussolino F, Ghigo D, et al. Nitrovasodilators inhibit thrombin-induced platelet-activating factor synthesis in human endothelial cells. Biochem Pharmacol. 1992;44:223-229. doi:10.1016/0006-2952(92)90004-3

120. Huang Y-Q, Li -J-J, Hu L, Lee M, Karpatkin S. Thrombin induces increased expression and secretion of angiopoietin-2 from human umbilical vein endothelial cells. Blood. 2002;99:1646-1650.

121. Rossaint J, Zarbock A. Platelets in leucocyte recruitment and function. Cardiovasc Res. 2015;107:386-395. doi:10.1093/cvr/cvv048

122. Cimmino G, Morello A, Conte S, et al. Vitamin D inhibits tissue factor and CAMs expression in oxidized low-density lipoproteins-treated human endothelial cells by modulating NF- $\mathrm{BB}$ pathway. Eur J Pharmacol. 2020;885:173422. doi:10.1016/j.ejphar.2020.173422

123. Lundwall K, Mörtberg J, Mobarrez F, Jacobson SH, Jörneskog G, Spaak J. Changes in microparticle profiles by vitamin D receptor activation in chronic kidney disease-a randomized trial. $B M C$ Nephrol. 2019;20:1-10. doi:10.1186/s12882-019-1445-4

124. Jia X, Xu J, Gu Y, Gu X, Li W, Wang Y. Vitamin D suppresses oxidative stress-induced microparticle release by human umbilical vein endothelial cells. Biol Reprod. 2017;96:199-210. doi:10.1093/biolre/bio142604

125. Blondon M, Biver E, Braillard O, Righini M, Fontana P, Casini A. Thrombin generation and fibrin clot structure after vitamin D supplementation. Endocr Connect. 2019;8:1447-1454. doi:10.1530/EC-19-0429

126. Guessous I. Role of vitamin D deficiency in extraskeletal complications: predictor of health outcome or marker of health status? Biomed Res Int. 2015;2015:1-13. doi:10.1155/2015/563403

127. Lips P, Cashman KD, Lamberg-Allardt C, et al. Current vitamin D status in European and Middle East countries and strategies to prevent vitamin D deficiency: a position statement of the European Calcified Tissue Society. Eur J Endocrinol. 2019;180:P23-P54.

128. Bouillon R, Rosen CJ, Mulder JE. Vitamin D and extraskeletal health. UpToDate. 2015;7.

129. Takeuti FA, Souza-Fonseca-Guimaraes F, Guimaraes PS. Applications of vitamin D in sepsis prevention. Discov Med. 2018;25:291-297.

130. Reijven P, Soeters P. Vitamin D: a magic bullet or a myth? Clin Nutr. 2020;39(9):2663-2674. doi:10.1016/j.clnu.2019.12.028

131. Bikle DD, Schwartz J. Vitamin D binding protein, total and free vitamin D levels in different physiological and pathophysiological conditions. Front Endocrinol (Lausanne). 2019;10. doi:10.3389/ fendo.2019.00317
132. Bikle D. Vitamin D: production, metabolism, and mechanisms of action. In: Feingold KR, Anawalt B, Boyce A, et al., editors. Endotext [Internet]. South Dartmouth (MA): MDText. com, Inc.; 2000. Available from: https://www.ncbi.nlm.nih.gov/books/ NBK278935/

133. Xie Z, Wang X, Bikle DD. Vitamin D binding protein, total and free vitamin D levels in different physiological and pathophysiological conditions. Front Endocrinol (Lausanne). 2020;11:40. doi: 10.3389 /fendo. 2020.00040

134. Cho M-C, Kim JH, Jung MH, et al. Analysis of vitamin D-binding protein (VDBP) gene polymorphisms in Korean women with and without endometriosis. Clin Exp Reprod Med. 2019;46(3):132. doi:10.5653/cerm.2019.00122

135. Mehramiz M, Khayyatzadeh SS, Esmaily H, et al. Associations of vitamin $\mathrm{D}$ binding protein variants with the vitamin $\mathrm{D}$-induced increase in serum 25-hydroxyvitamin D. Clin Nutr. 2019;29:59-64. doi:10.1016/j.clnesp.2018.12.005

136. Rossol M, Pierer M, Raulien N, et al. Extracellular Ca 2+ is a danger signal activating the NLRP3 inflammasome through $\mathrm{G}$ protein-coupled calcium sensing receptors. Nat Commun. 2012;3:1-9. doi:10.1038/ncomms2339

137. Sakem B, Nock C, Stanga Z, et al. Serum concentrations of 25-hydroxyvitamin D and immunoglobulins in an older Swiss cohort: results of the Senior Labor Study. BMC Med. 2013;11:176. doi:10.1186/1741-7015-11-176

138. Stover CM, McDonald J, Byrne S, Lambert DG, Thompson JP. Properdin levels in human sepsis. Front Immunol. 2015;6:24. doi:10.3389/fimmu.2015.00024

139. Ospina-Caicedo AI, Cardona-Rincón AD, Bello-Gualtero JM, et al. Lower levels of vitamin D associated with disease activity in Colombian patients with systemic lupus erythematosus. Curr Rheumatol Rev. 2019;15:146-153. doi:10.2174/ 1573397114666181015161547

140. Karasu E, Nilsson B, Köhl J, Lambris JD, Huber-Lang M. Targeting complement pathways in polytrauma-and sepsis-induced multiple-organ dysfunction. Front Immunol. 2019;10:543. doi:10.3389/fimmu.2019.00543

141. Nedeva C, Menassa J, Puthalakath H. Sepsis: inflammation is a necessary evil. Front Cell Dev Biol. 2019;7:108. doi:10.3389/ fcell.2019.00108

142. Sharma NK, Ferreira BL, Tashima AK, et al. Lipid metabolism impairment in patients with sepsis secondary to hospital acquired pneumonia, a proteomic analysis. Clin Proteomics. 2019;16:29. doi:10.1186/s12014-019-9252-2

143. Bashir NA, Bashir AAM, Bashir HA. Effect of vitamin D deficiency on lipid profile. Am J Lab Med. 2019;4:11-18. doi:10.11648/j.ajlm.20190401.12

144. Dibaba DT. Effect of vitamin D supplementation on serum lipid profiles: a systematic review and meta-analysis. Nutr Rev. 2019;77:890-902. doi:10.1093/nutrit/nuz037

145. Lee SH, Park MS, Park BH, et al. Prognostic implications of serum lipid metabolism over time during sepsis. Biomed Res Int. 2015;2015:1-8. doi:10.1155/2015/789298

146. Schwetz V, Scharnagl H, Trummer C, et al. Vitamin D supplementation and lipoprotein metabolism: a randomized controlled trial. J Clin Lipidol. 2018;12:588-596. e584. doi:10.1016/j.jacl.2018.03.079 


\section{Publish your work in this journal}

The Journal of Inflammation Research is an international, peerreviewed open-access journal that welcomes laboratory and clinical findings on the molecular basis, cell biology and pharmacology of inflammation including original research, reviews, symposium reports, hypothesis formation and commentaries on: acute/chronic inflammation; mediators of inflammation; cellular processes; molecular mechanisms; pharmacology and novel anti-inflammatory drugs; clinical conditions involving inflammation. The manuscript management system is completely online and includes a very quick and fair peerreview system. Visit http://www.dovepress.com/testimonials.php to read real quotes from published authors. 